\title{
Hylomorphism and Complex Properties
}

Published in Metaphysica 21 (2): 179-197

\begin{abstract}
Hylomorphism is the Aristotelian theory according to which objects are composites of form and matter. Form is what unifies the various parts of an object - the matter-into a cohesive whole. Some contemporary hylomorphists argue their theory applies beyond the realm of concreta, and that it explains the unity of various abstract entities. Not everyone agrees. Recent criticism alleges that hylomorphism fails to explain the unity of certain abstract entities, namely, complex properties-properties with other properties as proper parts. Here, I both respond to this criticism and show that and how hylomorphism extends to the domain of complex properties. By discussing hylomorphism's applicability to the hitherto unchartered domain of complex properties, I hope to defend its credentials as a general mereological theory.
\end{abstract}

Keywords: Hylomorphism, Complex Properties, Structural Properties, Form, Organizing Principle, Britton

\section{Introduction}

Hylomorphism is the Aristotelian theory according to which objects are composites of form and matter. ${ }^{1}$ Matter is the stuff out of which objects are constituted - the tissues, fluids, and minerals, for example, in a plant. Form is the principle that unifies various parts into a cohesive whole-the arrangement of tissues, fluids and minerals generative of a fully functioning plant. ${ }^{2}$ According to some of its contemporary adherents, hylomorphism is not just a theory of material objects, but a general theory of parts and wholes capable of explaining the unity of various concreta and abstracta.

But some are skeptical. Teresa Britton (2012) has argued that hylomorphism fails as a fully general theory of parts and wholes. She claims that hylomorphism cannot explain, or, rather, adds nothing to a genuine explanation of, the unity of certain abstract entities, namely, complex properties. Complex properties are properties that have other properties as proper parts. For example, mugginess is composed of high heat and high humidity, and color is composed of hue, saturation, and brightness. According to Britton, hylomorphism cannot explain the unity of complex properties because form has no unifying role to play in the generation of complex properties from other properties. This stems from the fact that complex properties are, we are told, mere summations or conjunctions of other properties: mugginess just is high heat and high humidity, and color just is hue, saturation, and brightness. While plant parts need to follow a certain structural recipe to

\footnotetext{
${ }^{1}$ For historical discussions of hylomorphism, see Ainsworth (2016) and Pasnau (2010).

2 The ontological status of form is a topic of serious debate for contemporary hylomorphists. Some take form to be a principle of unity or an arrangement of parts (broadly, for example, Fine (1999), Johnston (2006), and Koslicki (2008)), others take it to be a dynamic power, process, or operation (broadly, for example, Jaworski (2016), Koons (2014), Marmadoro (2013), Rea (2011), and Skrzypek (forthcoming)), while still others claim it is an inherent, constitutive property or principle of actuality (broadly, for example, Brower (2014) and Oderberg (2007)). I wish to stay neutral on this matter here, but should note that Britton understands form in the first sense, and so, for the purposes of this paper, I follow her. For further discussion of these various strains of hylomorphism, see Heil (forthcoming) and Koons (2014).
} 
generate a fully functioning plant, a complex property is a mere heap or fusion of properties, and so, requires no such structural principle.

Britton explores a novel and fascinating application of hylomorphism, but, I will argue, her criticism fails. My aim in this paper is to show that form has a role to play in the domain of complex properties. In doing so, I defend hylomorphism as a general mereological theory; or, minimally, I show that if hylomorphism fails as a fully general mereological theory, then it is not because of its failure to accommodate complex properties at least.

My motivation is straightforward. Hylomorphism is a powerful, pedigreed, and growingly popular mereological theory. Complex properties are hitherto uncharted territory for hylomorphism, and so, showing that and how the principles of form and matter can illuminate their mereological structure will grow the theory's philosophical utility. If I can show that hylomorphism is a fully general mereological theory (or again, minimally, more general than has been alleged), then we have even more reason to accept it.

The paper is split into two main sections. The first recapitulates and distills recent criticism of hylomorphism and the second lays out my reasons for thinking that criticism is off the mark. Along the way, I consider and respond to pertinent objections.

\section{Hylomorphism and Its Limits}

Hylomorphism is a rival to 'conventional' mereological theories. In contrast to conventional theories which posit only parts and wholes, hylomorphism countenances parts (i.e., matter), wholes, and a sui generis principle, form. Forms are 'unifying principles,' 'formal relations,' or 'organizing structures.' Hylomorphism's additional posit allows it to distinguish between genuine or 'robust' composite entities, like water molecules, trees, and airplanes, and abundant or ad hoc composites, such as trout-turkeys, piles of rocks, and other arbitrary summations. So understood, hylomorphism is a theory of restricted composition-a commonsense alternative to compositional nihilism and universalism. As Britton (2012: 146) summarizes, 'The presence of an organizing principle explains why parts together create objects. Its absence explains why parts together constitute only collections or groups.' In short, hylomorphism distinguishes genuine composites from mere heaps by appealing to a genuine-object-producing principle, form.

Forms circumscribe objects by restricting the range of parts that can compose an object. Forms provide the mereological recipes of objects. ${ }^{3}$ [Forms] explain what parts could be added to the whole. So for instance, the organizing principle of a telephone makes it such that a telephone cannot have an engine as a part. They explain which parts are necessary, as a heart or a heart substitute for mammal[s]' (Britton 2012:

${ }^{3}$ I borrow the phrase from Koslicki (2008: 172). 
146). In short, forms generate genuine objects by allowing the right kinds of parts into the mix, and by prohibiting the wrong kinds. A hammer-shaped piece of chocolate cannot be a genuine hammer; only hammer-shaped hunks of steel (or some other suitable material) are genuine hammers-objects that can actually carry out the functions characteristic of hammers. ${ }^{4}$

Beyond delimiting the kinds of parts that can compose an object of a certain kind, forms also dictate how those parts may be arranged. '[T] he organizing principle explains why parts have the particular arrangement that they do and which arrangements are possible for that object. For airplanes, wheels placed on the bottom work best' (Britton 2012: 146). What differentiates an airplane from an arbitrary collection of aeronautical parts is the arrangement of those parts into an object that can takeoff, fly, and land; an object with wheels just on top of the fuselage can neither takeoff nor land, and so, is not an airplane, a genuine object.

Hylomorphism does a fine job explaining the unity of concrete objects, but some contemporary hylomorphists feel no need to stop there. Some have extended Aristotle's theory to the abstract realm of propositions, logic, aesthetic objects, and even actions and events. ${ }^{5}$ In the abstract realm too, Britton thinks postulating an organizing principle does good on differentiating between genuine and ad hoc entities. Supposing that linguistic, mathematical, and musical entities are abstract, form distinguishes between genuine sentences, formulae, and scores from ad hoc collections of parts. Britton (2012: 147-8) explains: 'The organizing principle of syntax separates genuine linguistic objects such as propositions from word jumbles. The rules of algebra separate legitimate algebraic equations from a nonsense sequence of variables and operations. The principles of music theory distinguish the noise generated from random notes on a page from genuine music.' The phrase 'Potatoes eat we mashed' is nonsense because it does not follow the formal recipes of syntax. To constitute a genuine sentence ('we eat mashed potatoes'), the words in the jumble would have to follow the structural constraints of syntactical forms.

Up to this point, Britton claims form has a role to play in differentiating genuine from ad hoc wholes. But she thinks form fails to contribute to an explanation of the unity of a certain sort of abstracta: complex properties, properties that have other properties as proper parts. Britton (2012: 149) provides some examples: color is hue, saturation, and brightness; sound is pitch, timber, and loudness; being muggy is high heat and high humidity; personality is wit, mannerisms, and character traits. Britton assumes for the sake of argument that (a) such complex properties exist (2012: 149), (b) that they are abstracta instantiated in physical space (2012: 149, n. 6), and (c) that complex properties and their parts are necessarily collocated (2012: 149). Allow me to elaborate on (b) and (c) briefly before moving on.

\footnotetext{
${ }^{4}$ A hammer-shaped piece of chocolate would be, Aristotle tells us, a hammer only in name.

${ }^{5}$ See, for instance, Dutilh (2012), Evnine (2016), Fine (1994, 1999), Johnston (2006), and Koslicki (2008). For relevant discussion, see McDaniel (2010: 412-414) and Oderberg (2014).
} 
The idea that properties are best conceived as abstracta is nothing new. However, Britton makes it clear that her interest is in the instances of abstract properties. Moreover, she notes (2012: 149, n. 8) that her argument would apply to complex properties conceived as particulars, as modes or tropes, too. So, our focus is on particular complex properties, whether they are instances of one and the same universal or distinct but exactly resembling tropes.

That complex properties and their component properties are collocated is a less familiar, though straightforward point. The basic idea is this: hue (and brightness and saturation) is instantiated everywhere the color it is a part of is instantiated. The parts of complex properties are instantiated exactly everywhere the whole they compose is instantiated. For, how might the hue of some color 'float away' from the space-time region the color it is a part of is instantiated in? And how could the hue of some color be in only a portion of the space-time region the color it is a part of is instantiated in?

With these preliminaries in mind, we can examine Britton's argument against hylomorphism as an explanation of the unity of complex properties.

What would it mean to extend hylomorphism to the mereology of properties? It would mean that we add an organizing principle to the part and whole duo. Let us take color as an example. Color is hue, saturation, and brightness. It is a genuine property, so, on the hylomorphic account, it would be "organized robustly." But right here we see the problem. Color is just hue, saturation, and brightness. Nothing more, not even a modest organizing principle, is needed. So too with the other properties used as examples here. Mugginess is high heat and high humidity, nothing more required. One's personality is just a collection of its component traits. No additional organization seems to be needed in a complete description of the whole. This point is simple. An organizing principle is not necessary in a mereological ontological formula for properties. (2012: 149)

Complex properties, we are told, are not the sorts of things which require robust organizing principles. Complex properties are conjunctive in nature, and so, there is no need for form to organize the conjuncts, the component properties, into something above and beyond their summation. Britton (2012: 149-50) continues:

If we postulated an organizing principle that unified the parts of color, sound, personality, etc. as wholes, that principle would best be described as summation of parts. But summation is not robust. And summation would also be the organizing principle behind ad hoc properties, such as the conjunction of being red and being round. 
In short, complex properties—both genuine and ad hoc—are mereological heaps, and form cannot say which heaps are genuine versus ad hoc. A heap is a heap is a heap. And so we have reached the limits of hylomorphism. ${ }^{6}$

\section{Hylomorphism Regained}

To recapitulate: hylomorphism is useful because it distinguishes between genuine versus ad hoc unities.

Complex properties are heaps and the arrangement or structure of a heap makes no difference to its unity, so, an organizing principle like form cannot distinguish genuine complex properties from ad hoc complex properties. So, hylomorphism does not do us any good in the realm of complex properties.

But is it obvious that complex properties are mere heaps with no use for forms? Is color just hue, saturation, and brightness, full stop? I am skeptical. First, I challenge the view that complex properties are mere heaps via counterexample. Next, by way of sketching an error theory, I argue Britton's conception of complex properties - which undergirds her attack on hylomorphism—is the result of incautious ontology. The final result is an ontology in which forms play the same organizing role in complex properties as they do in the rest of the abstract and concrete realms.

\subsection{Is the 'Just is' Relation Just Wrong?}

Britton thinks a complex property like mugginess just is high heat and high humidity. In this case, she may be right (more on this later). But in other cases-important cases her conception of complex properties ought to be able to handle- - she misses the mark. Here are three such cases, all of which seem to require something like an organizing principle.

(i) A dispositional property, or power, capacity, or potentiality, is a property for or directed at a manifestation. Examples include solubility and charge. Solubility is a property that endows its possessor with the ability to dissolve. Salt, given the right conditions, when engaged properly with a solvent, will dissolve. Solubility is for dissolving; it is directed at the property being dissolved. Negative charge is directed at, ready for, an attraction manifestation with positive charge and a repulsion manifestation with another negative charge. In short, dispositions are properties that point beyond themselves. ${ }^{7}$

\footnotetext{
${ }^{6}$ Britton (2012: 152) also chalks up hylomorphism's failure to the collocation of complex properties and their parts. The arrangement of aeronautical parts makes a difference to whether or not they form an airplane because the parts are smaller than whole. One part goes here, another part goes there, and the result is a different whole. When parts are smaller, either physically or in representation, than the whole they compose, arrangement matters. But if hue, saturation, and brightness all occupy the same exact region of space-time, it is hard to see (or imagine) how their arrangement matters. All of the parts are exactly everywhere the other parts, and so the whole, are-there can only be one 'arrangement.' I discuss this further at the end of $₫ 3.1$.

${ }^{7}$ For a wide-ranging discussion of dispositions, see Mumford (1998).
} 
It is widely agreed that dispositions are identified and individuated by their manifestations. ${ }^{8}$ That is, for example, what it is to be negative charge is to manifest in certain ways with certain partners in certain circumstances. If some unidentified particle attracted rather than repelled electrons, we would not suppose that particle had the dispositional property of negative charge.

So understood, dispositions are complex. Specifically, dispositions are properties composed of stimulus and manifestation conditions. For, if what it is to be some disposition D is to manifest some way, M, in some conditions with the right partners, $\mathrm{C}$, then it seems right to think D is composed of, in some way, $\mathrm{M}$ and C. (Or, you might suppose disposition $\mathrm{D}$ is composed of some occurrent property $\mathrm{O}$ (the way the object possessing $\mathrm{D}$ is prior to stimulus) and the manifestation $\mathrm{M}$ it is directed at.)

Now, if a disposition is a capacity for some manifestation, then it is clearly not a mere summation of its parts. Manifestation M comes about in virtue of disposition D being in circumstances, and with partners, C. $\mathrm{M}$ is the result of $\mathrm{D}$ being in $\mathrm{C}$; perhaps $\mathrm{M}$ is caused by $\mathrm{D}$ being in $\mathrm{C}$. Whatever it is, the relation between $\mathrm{D}$ and $\mathrm{M}$ is not summation; for, it is very clearly asymmetrical. If this is right, dispositional properties cannot be heaps, and so, perhaps dispositional properties have organizing principles. ${ }^{9}$

One might object that dispositions are obscure, and, more specifically, that the very notion of a property pointing beyond itself makes little sense. And, if it does make sense, then it implies manifestations are somehow contained in dispositions, and this, surely, is very obscure. ${ }^{10}$ In response to the first, general worry, I have nothing very illuminating or novel to say. Dispositions have proven themselves incredibly useful in metaphysics and the philosophy of science, and so, if one cannot understand them, all the worse for you. ${ }^{11}$ In response to the second worry, I might note that some metaphysicians have worked out views which analyze the 'contained in' locution into more familiar entities and concepts (see, for example, Tugby (2013), who advances a Platonic view). But, more importantly, there is no need to suppose dissolving is actually 'in' the soluble substance. Rather, we need only to recognize that what it is to be solubility, for example, is to be that in

\footnotetext{
${ }^{8}$ For discussion and a recent modification of this standard view, see Vetter (2014).

${ }^{9}$ A plausible candidate for the organizing principle in dispositions is a material conditional: $\mathrm{x}$ has $\mathrm{D}$ iff $((\mathrm{x}$ in $\mathrm{C}) \rightarrow \mathrm{M})$. For, it properly captures the asymmetry between disposition and manifestation, restricting what can be brought about by what. Now, the project of analyzing dispositions and dispositional ascriptions into conditionals and conditional statements is a troubled one. Even highly sophisticated conditional accounts are subject to counterexample. Be that as it may, the idea that a conditional can, broadly, capture what is going on with dispositions — even if imperfectly-is all I really need and hope to gesture at. For defense of the conditional analysis, see Choi (2006) and Lewis (1997). For critique, see Bird (1998), Martin (1994), and Vetter (2014). For discussion, see Choi \& Fara (2006/2012: \$1). ${ }^{10}$ Armstrong (1997: 79), for instance, thought it implied the existence of Meinongian objects.

${ }^{11}$ I confess that I cannot understand what a wholly non-dispositional property, or 'quiddity,' could be. Cf. Hawthorne (2001) and Shaffer (2005).
} 
virtue of which some substance is liable to dissolve, and this doesn't entail any obscure 'contained in' metaphysics. ${ }^{12}$

(ii) Some complex properties, like mugginess, are straightforwardly conjunctive. High heat and high humidity can be slapped together in any which way to yield an instance of mugginess. For other complex properties, however, such haphazard union is intolerable. Consider a molecule of butane. It has four carbon atoms and ten hydrogen atoms as constituents. Some of the carbon atoms are bonded to two hydrogen atoms and two carbon atoms, but others are not. Figure 1 below depicts the bonding arrangement of butane. So what of the complex property, being a butane molecule? Could it be composed of being a carbon atom (four times over) and being a hydrogen atom (ten times over) in any which way? Clearly, it seems not. How the parts of being a butane molecule (and numerous other properties) are arranged is vital. For, if the very same parts were arranged differently, a different molecule, and so, complex property, would result, namely, isobutane. ${ }^{13}$

Figure 1. Butane (left) and iso-butane (right) (Creative Commons)
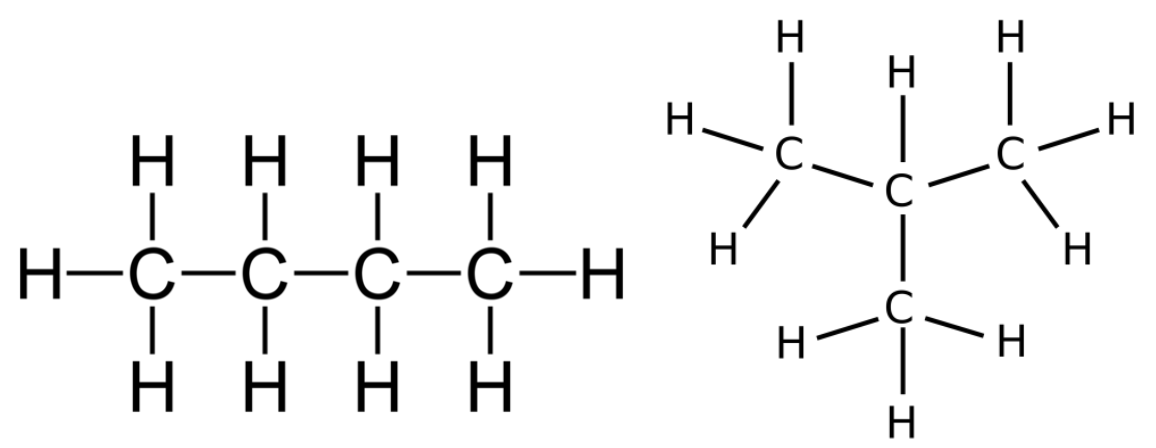

David Lewis (1986) argued famously that complex properties such as being butane, what he called structural properties, spelt trouble for ontologies of universals. Whether or not Lewis was right is not our

\footnotetext{
${ }^{12}$ For a discussion of the 'contained in' locution and why it needn't be ontologically weighty, see Martin (2008: 1-11, 2434); cf. Martin and Pfeifer (1986). One might object now that, so understood, dispositions are merely complex in definition, not being: the essence of a disposition is complex, but the disposition itself, a property, isn't complex. In response I should note that this depends entirely on how we understand the ontology of dispositions. For instance, on Tugby's view, dispositions are straightforwardly complex in being: they're property-relation complexes (cf. Lowe 2006: 121-127). Although I am inclined to reject Tugby's view, it is an option here, and absent some mutually agreed upon conception of dispositions that sinks my counterexample, my point stands.

${ }^{13}$ Of course, there are also dozens of ad hoc jumbles that could result from the haphazard union of four carbon and ten hydrogen atoms that don't correspond to any actual organic molecules.
} 
concern here though, as our focus is on property instances or particular properties. ${ }^{14}$ What concerns us is that a class of complex properties very straightforwardly requires organizing principles. Structural properties are a clear counterexample to Britton's just is account of complex properties. ${ }^{15}$

(iii) Let me consider a third and final example; but first, some background.

In debates about the composition of objects, it is argued that wholes cannot be just the sum of their parts because wholes have properties their parts do not. ${ }^{16}$ According to Leibniz's Law, if two objects have different properties, they cannot be numerically identical. Imagine, for example, a table and the cloud of particles composing it. The cloud of particles cannot survive a change in parts. If at $t_{1}$ the cloud has particles $\mathrm{a}, \mathrm{b}$, and $\mathrm{c}$, but later at $\mathrm{t}_{2}$ has particles $\mathrm{a}, \mathrm{b}$, and $\mathrm{d}$, we no longer have the same cloud of particles. A cloud of particles, like any heap, has its parts essentially. But, the table can survive a change in parts. If, while my family and I eat dinner, the table exchanges particle $\mathrm{c}$ for particle $\mathrm{d}$, it is plausible that the table we finished eating dinner on is identical to the table we started eating dinner on. But this means clouds of particles and the tables they compose have different persistence conditions — different properties—and so, are not one and the same thing. ${ }^{17}$

Now, consider the complex property being a tuna. Suppose for the sake of argument that being a tuna is composed of the properties finned, predatory, and great for sushi. Any object that is a tuna instantiates the property being a tuna. On Britton's account, any object that instantiates being a tuna will also instantiate the properties finned, predatory, and great for sushi. For, to be a tuna just is to be finned, predatory, and great for sushi. Now, imagine a tuna, Jack, who sees some small fish up ahead and picks up his speed to ambush them. When Jack gets close to the fish, he realizes they are just lures attached to a net. But Jack is going so fast that he hits and ploughs right through the net, severing off all his fins. Jack no longer instantiates the property finned.

Before Jack hit the net, at $\mathrm{t}_{1}$, he instantiated being a tuna. At $\mathrm{t}_{1}$, Jack also instantiated finned, predatory, and great for sushi. At $\mathrm{t}_{2}$, after he hit the net, Jack did not instantiate finned but he did instantiate predatory and great for sushi. But it seems incredibly plausible that Jack still instantiated being a tuna at $\mathrm{t}_{2}$. The severing of Jack' fins couldn't have turned him into something besides a tuna. A tuna without fins is still a tuna, just as a human without legs is still a human, and a tree without leaves is still a tree. But on Britton's view, Jack doesn't instantiate being a tuna at $t_{2}$. For, being a tuna just is to be finned, predatory, and great for sushi. Since complex properties are mere summations on Britton's account, they have their parts essentially

\footnotetext{
${ }^{14}$ For further discussion of structural properties, see Koons \& Pickavance (2017: 215-219).

15 Though his concerns are quite different from ours here, see Scaltsas (1994: 77-86) for a discussion of forms and structural properties.

${ }^{16}$ For an overview of this debate, see Thomasson (2010).

${ }^{17}$ For further discussion, see Bennett (2004).
} 
(just like the cloud of particles composing the dinner table). Therefore, if being a tuna loses one of its constituent parts, it no longer exists. But that is just to say that Jack is no longer a tuna at $t_{2}$ ! If it is plausible that Jack is still a tuna after he hits the net, that means being a tuna has different persistence conditionsdifferent properties - than the mere summation of finned, predatory, and great for sushi. And that means being a tuna is not just being finned, predatory, and great for sushi. And, perhaps, that means being a tuna is organized more robustly than a mere heap. ${ }^{18}$

Now, there is a move Britton could make to avoid this result. She might respond that certain constituent properties of being a tuna are more important than others. For instance, perhaps being great for sushi, but not being finned, is what's really important for being a tuna. (More realistically, I suppose it is something like having the right genetic composition, breeding behavior, et cetera.) In other words, one might suppose certain constituent properties are essential to the complex properties they compose, and others not. So, while Jack does not instantiate all of the constituent properties of being a tuna at $\mathrm{t}_{2}$, he does instantiate those essential to being a tuna. In this way, Jack might still be a tuna after the accident.

Hawley and Bird (2011) have defended a view of natural kinds congenial to such a response. They argue natural kinds, such as being a tuna, are conjunctive properties composed of essential and accidental properties. ${ }^{19}$ So Britton might rely on this framework and say, again, that certain complex properties, though united by nothing more than conjunction, have an essential-accidental 'structure' that obviates my last objection. Although complex properties are heaps, they do not themselves have the persistence conditions of heaps.

While I think this response may work for complex properties like being a tuna, I am skeptical it will work elsewhere. For instance, it seems both high heat and high humidity are essential to being muggy. If it is hot out, but not humid, the air is just hot, not muggy. Someone with just wit and mannerisms but no character traits does not, it seems, have much of a personality. Likewise, if you change the hue of some color while even keeping its saturation and brightness constant, the result is a different color. Of course, you cannot remove the hue from a color like you can Jack's fins; some hue, saturation, and brightness or other are all necessary ingredients of color. Though this makes color an interestingly different example from mugginess and personality, I think the identity of a particular color depending on its particular parts (for example, Forest Green depending on $61 \%$ saturation), vindicates my point all the same. ${ }^{20}$ So, even helping oneself to Hawley

\footnotetext{
${ }^{18}$ Note that, if right, this shows being a tuna requires an organizing principle in a way quite different than the previous examples do. For, a difference in persistence conditions is quite different from parts following a mereological recipe-it just shows that being a tuna is something 'over and above' being finned, predatory, and great for sushi.

${ }^{19}$ Cf. Elder's (2007) discussion of property clusters and master properties.

20 The example of color is discussed in greater detail below in $\$ 3.2$.
} 
and Bird's account—which I have assumed for the sake of argument is an untroubled and sufficientlymotivated move-recourse to an essential-accidental distinction will not help in all cases. ${ }^{21}$

If these counterexamples sound plausible, then the just is relation may not be the whole story; organizing principles seem to have a role to play in certain complex properties.

Before moving on, allow me to address a lurking objection. You might think I have counterexamples to Britton's account of complex properties only because I have flouted her assumption that complex properties and their parts are collocated. It is not clear that the parts of dispositional properties are collocated; some manifestations might not even exist, and so, are not located at all. The parts of being butane and being butane itself are clearly not collocated, and the parts of being a tuna, such as predatory, are not obviously located at all (where could behavior be?). In short, I have changed the rules of the game.

In response: if the examples above are genuine complex properties—and why would they not be, if something like mugginess is? - then Britton's collocation criterion may just be wrong, or at least not universally true. If that is right, then Britton has flouted, or artificially narrowed, the rules of the game, not me. The domain and nature of complex properties may be far richer and more intricate than Britton thinks. In fact, as I show in the next section, the story of complex properties is more, well, complex, than it initially appears.

\subsection{Ontology Gone Wrong}

If the above counterexamples are right, and not all complex properties are mereological heaps, where has Britton gone wrong? My thought is that the complex properties she relies on as examples are ontologically vacuous - they have only what Campbell (1990: 110) calls a 'specious novelty.'22 I suspect things went awry with an incautious, implicit shift from language to ontology.

Consider again being muggy, the summation of being hot and being humid. Britton thinks this genuine property is organized no more robustly than an ad hoc property like red-round, the conjunction of being red and being round. But how and why could this be? Like me, you might find it puzzling that an account would claim that there are neatly demarcated constituents of the world—genuine complex properties—but that they cannot be mereologically distinguished from unrestricted Lewisian monstrosities-

\footnotetext{
${ }^{21}$ For different accounts of natural kinds and their essences (if there are any), and general discussion of complex essences, see Dumsday (2010) and Oderberg (2011). One thing to note, especially in Oderberg (2011), is that natural kinds or essences are unified principles which dictate what properties an object has, and are not merely heaps or sets of properties (cf. Lowe 2006: 25-28). Thus, if one is attracted to such accounts, the move towards a Hawley-Bird account of complex properties might seem especially unsatisfactory.

${ }^{22}$ For a skeptical take on complex properties, see Heil (2012: 95-97). Armstrong (1997) countenances numerous such properties, but claims many, such as red-round and mugginess, are ontologically uninteresting.
} 
ad hoc properties like red-round. What could explain the supposed mereological isomorphism of the genuine with the ad hoc?

One explanation is that Britton's account countenances certain complex properties as genuine that are, in fact, not so genuine. That is, perhaps being muggy, for example, is an ad hoc property. But how could Britton possibly be so mistaken? Surely, being muggy is a genuine property; we make true claims about the air instantiating it all the time. Well, of course we do, but that does not make being muggy a genuine constituent of the world; it makes being muggy something we claim—something we say-about the world, whatever it is deep down, genuinely, fundamentally.

I suspect Britton read her ontology—her candidates for genuine complex properties—off our common linguistic practices. More precisely, I suspect she mistook predicates for properties; she let the linguistic tail wag the ontological dog. As Heil (2003: 6) would put it, Britton was led astray by the Picture Theory of Representation:

The core idea is that the character of reality can be 'read off' our linguistic representations of reality. A corollary of the Picture Theory is the idea that to every meaningful predicate there corresponds a property.... The Picture Theory encompasses the idea that elements of the way we represent the world linguistically 'line up' with elements of the world.

Put differently, one might say the Picture Theory has it that there is a one-to-one correspondence between truths and their truthmakers. If it is true to say of some lump of bronze that it forms a statue, there must be, in addition to the bronze, a statue. Or, if we predicate is red of numerous objects, there must be some shared feature of reality that is common to all such objects. But why suppose this is so? Why suppose that for some word there must be some worldly correspondent (cf. Heil 2003: 49)?23

Now, this explanation rests on a sparse conception of properties being right, and this is something I cannot argue for here. ${ }^{24}$ So, take this all as something like a preliminary, rather than final, diagnosis.

That said, if the story I am sketching here is on to something, it is clear why Britton would find no role for forms in complex properties. The complex properties she discusses seem to be nothing more than heaps because they are in fact heaps. If you take your ontological cues from language, you will inevitably countenance heaps as genuine constituents of the world because you need your properties to mirror your predicates. Since we truthfully predicate being muggy of the air, there must be amongst the furniture of the

\footnotetext{
${ }^{23}$ For further discussion and critique of the picture theory, see Heil (2003: 22-30).

${ }^{24}$ For a conception of properties and parthood Britton could rely on to resist the metaphysics underlying my error theory, see Paul (2002). For more on sparse conceptions of properties, see Schaffer (2004) and Swoyer (1996). For an overview of sparse and competing abundant conceptions of properties, see Allen (2016: ch. 5).
} 
world the property of being muggy. And since being muggy means the air is both hot and humid, the 'genuine' complex property being muggy just is being hot and being humid. Because there is a predicate, $\mathrm{F}$, there must be a corresponding property, F, and if the predicate F means y, the property F must also be y. And if $\mathrm{y}$ means $\mathrm{a}$ and $\mathrm{b}$, the property $\mathrm{F}$ just is a and $\mathrm{b}$. Linguisticism run amok.

There are two objections one might raise at this point. (i) First, one might object that my error theory undermines my own argument in \$3.1. If I am right, and complex properties are posited only because we (incautiously) follow linguistic practices, how can I rely on complex properties as counterexamples to Britton's account? There are two responses to this objection. First, assume it is well-placed. Assume the ontological picture gestured at by my error theory undermines any talk of complex properties, for there are no such things as complex properties. I would be wholly content if this were true. If there were no such things as complex properties, then hylomorphism would have fewer cases to account for, fewer domains in which it would need to prove its worth. In short, if right, this objection simply makes it easier for hylomorphism to be a general mereological theory, and that is just fine with me. Second, to my lights, dispositional, structural, and natural kind properties are far more legitimate, from an ontological point of view, than putatively complex properties like mugginess. These sorts of properties factor into our empirical and philosophical theories to a far greater extent and degree than do properties like mugginess. ${ }^{25}$ Given this, and no clear argument for why or how my error theory generalizes to all complex properties, I think I am justified in relying on counterexamples to critique Britton's account.

(ii) Second, consider again the example of color. It seems to get around the linguistic worry I raise for properties like mugginess quite easily. Color does not mean, in ordinary linguistic practice, the sum of hue, saturation, and brightness, and so, it seems odd to think we posit color as a complex property just in virtue of talking about it. In other words, color is not something we just say about the world and thereby posit in our ontology; color very much seems to be an objective feature of the world (or our sensory system interacting with the world). And given our ability to manipulate the hue, saturation, and brightness of colors, it seems we also have good reason to suppose color is genuinely complex. In sum, one might object that my error theory does not explain all of the considered examples.

In response, recall that in $\$ 3.1$ above, I noted the parts of color-hue, saturation, and brightnessappear to be necessarily co-instantiated: where there is hue, there is, necessarily, some brightness and saturation. It seems impossible for the component properties of color to come apart: while you can change the

\footnotetext{
${ }^{25}$ You might think that mugginess is, given phenomenological data, more natural or legitimate than some other putatively complex properties. We experience mugginess, not the mere co-instantiation of high heat and high humidity. I am unconvinced. To my lights, such phenomenological data is hugely perspectival, and so, not to be relied on for ontological guidance. Thanks to Allan Hazlett for bringing this to my attention.
} 
hue of some color, you cannot eliminate the hue of some color. ${ }^{26}$ This necessary co-instantiation, to me, suggests that color is not in fact mereologically complex. That is, given the putative parts of color cannot come apart like, say, the parts of being a tuna or being muggy can, perhaps color has no such parts. And if color is not a complex property, then there is no need for my error theory to accommodate it. Now, I acknowledge that just because the xs are necessarily instantiated with the ys that it does not mean there is no distinction between the xs and ys, and it certainly does not prove that the xs are identical to the ys. Being triangular is necessarily co-instantiated with being trilateral, but the two are distinct properties. I have my suspicions nonetheless.

To my lights, what is really going on in the case of color is that it is 'composed' of abstract parts. ${ }^{27} \mathrm{By}$ abstract here I mean the product of Aristotelian partial consideration, not transcendent like Platonic forms. The basic idea is that hue, saturation, and brightness are different aspects of a single unified thing, color, which we discern, grasp, and diversify mentally. Consider, for example, an apple. We can consider just the redness of the apple, or just its roundness-redness or roundness themselves. We do so by mentally stripping away, by abstracting from, all the features of the apple besides the ones we are interested in. The product of such a process is a mental entity though; the apple and its roundness and redness are one and the same thing, a truly unified whole, out in the world. My thought is that hue, saturation, and brightness are just like this: they are mental abstractions, not genuine mereological components, of color. ${ }^{28}$

But you may not find this story persuasive. For, if color is metaphysically simple, then how can we, even through a process of abstraction, make it complex? Doesn't the fact that we pick up on and isolate the 'parts' of color suggest there is something in the world, in color, that we're picking up on? In other words, how can we abstract fine-grained 'properties' like hues, saturations, and levels of brightness, if there are no such things? 29

Consider, instead of an object and its properties, a number, say, $\pi . \pi$ has various 'properties' and stands in various relations with other numbers. For instance, $\pi$ has the 'property' of informing us of the circumference of a circle when multiplied by the circle's diameter. This 'property' is not, by my estimation, an entity in or constitutive of $\pi$; it is simply as aspect of $\pi$, a way it is, or in more Aristotelian terms, a 'part' of its nature. None of this commits us to saying $\pi$ is a metaphysically structured entity, somehow composed of a 'property' that informs us of the circumference of a circle when multiplied by the circle's diameter. Indeed,

\footnotetext{
${ }^{26}$ For the view that properties can come apart so, see Schaffer (2003).

${ }^{27}$ I am also skeptical that we manipulate or change the hue, brightness, or saturation of colors at all. To me it seems that we simply annihilate and create new colors when 'altering' these constituent properties. That is, I doubt the world is like a multi-dimensional color space where we can simply pick and choose the values of hue, saturation, and brightness independently for colors.

${ }^{28}$ For more on abstraction, see Campbell (1990), Heil (2012: 15-18), Lowe (1999), and Schaffer (2010: 46-50).

${ }^{29}$ Many thanks to an anonymous reviewer for bringing this objection to my attention.
} 
what would it even mean to say a number was constituted this way, in the same way an object is constituted, at least by anything other than other numbers?

My suggestion is that we think of hue, saturation, and brightness like this: as features but not metaphysical constituents of color. Now, I submit, that this analogy is all I have in defense of this suggestion. Should you not find it satisfactory, I have nothing else to persuade you save other analogies. But, this needn't imply you must accept Britton's view in the case of color. For the fact that hue, saturation, and brightness are of necessity co-instantiated suggests another response: that color is indeed complex, but requires a form. ${ }^{30}$ Just as my example of Jack the tuna above suggested, forms play the role of imposing existence conditions on properties. As this suggestion goes, a part of the existence conditions of color is that some hue, saturation, and brightness are co-instantiated. If this is right, even if the constituent parts of color can be slapped together any which way and still yield a color, they must follow the formal recipe of color: contain a hue, saturation, and brightness. Understood in this way, the form of color would be, as Aristotle tells us in Metaphysics VII, color's essence, the what it is to be color. If this is right, even if you fail to be convinced by the story of abstraction, and take colors to be genuinely complex, you needn't, with Britton, suppose they have no role for form.

So, where does this leave us? I think the complex properties discussed so far, and in general, fall under one of three headings: Genuine, Heapish, or Simple. Genuine complex properties include dispositional, structural, and natural kind properties; they appear genuinely complex and have a role for form-as I have argued, each required an organizing principle, or at least pointed towards one. Heapish properties are those like being muggy which, if I am right, are not really properties at all; they are merely sets or heaps of simple properties collectively gestured at by predicates. Lastly, Simple properties are putatively complex properties that are actually simple, perhaps like color, which, as simple, do not fall within hylomorphism's purview. While I do not take this categorization to be ironclad or foolproof, I cannot think of any counterexamples to it, and, more importantly, it shows that and how hylomorphism applies neatly in the realm of complex properties.

\section{Conclusion}

I have argued the hylomorphic principle of form has a role to play in the realm of complex properties. I did so by considering and responding to Britton's recent account of complex properties, an account which purported to show that forms or organizing principles were explanatorily useless. I then provided an error theory for Britton's account, arguing her conclusion was the result of incautious ontology. More specifically, I argued she mistook predicates for properties and, in doing so, countenanced certain pseudo-complex

\footnotetext{
30 Again, many thanks to an anonymous reviewer for bringing this insightful suggestion to my attention.
} 
properties which, on their face, had no need for forms. But, given the properties were pseudo-properties (or were actually simple) they presented no good reason to declare hylomorphism's explanatory limits had been reached.

One might nonetheless worry that I have missed something, or that some of Britton's examples survive my criticism, or that, perhaps, there are other complex properties neither of us has considered yet, and so, counter that while maybe some complex properties have a role for form, not all complex properties do. ${ }^{31}$ Here, assuming the properties in mind pass an ontological litmus test, I acquiesce: there may indeed be certain complex properties with no role for form. But, I take it, nonetheless and at minimum, that I have shown form does have a role to play in some complex properties. Even if there are genuine complex properties with no use for form, at least we know hylomorphism is more general than critics allege. Either way, until opponents of hylomorphism make a case for these problem properties (instead of merely supposing they exist) I suggest we recognize hylomorphism as a fully-general mereological theory. ${ }^{32}$

\section{References}

Ainsworth, Thomas (2016). "Form vs. Matter" in Edward N. Zalta, ed., Stanford Encyclopedia of Philosophy, https://plato.stanford.edu/entries/form-matter/

Allen, Sophie (2016). A Critical Introduction to Properties (London: Bloomsbury)

Armstrong, David (1997). A World of States of Affairs (Cambridge: Cambridge UP)

Bennett, Karen (2004). "Spatio-Temporal Coincidence and the Grounding Problem” Philosophical Studies 118: $339-71$

Bird, Alexander (1998). "Dispositions and Antidotes” Philosophical Quarterly 48: 227-34

Britton, Teresa (2012). “The Limits of Hylomorphism” Metaphysica 12: 145-53

Brower, Jeffrey (2014). Aquinas's Ontology of the Material World: Change, Hylomorphism, and Material Objects (New York: Oxford UP)

Campbell, Keith (1990). Abstract Particulars (Oxford: Blackwell)

Choi, Sungho (2006). "The Simple vs. Reformed Conditional Analysis of Dispositions” Synthese 148: 369-79

\footnotetext{
31 In correspondence, Britton has suggested that hylomorphism may apply to some complex properties, such as my counterexamples, but stuck to her guns regarding complex properties where the parts are collocated with the whole. While I am happy with the concession, I am suspicious of her insistence on cases of collocation. I simply cannot think of any genuinely complex properties where the parts are collocated with the whole. This may be a failure on my part, but it may also be the heart of our disagreement.

32 Thanks to Niklas Andersson, Will Bell, John Heil, Lauren Olin, James Peters, Jeremy Skrzypek, Qiong Wu and audiences at Rhodes College, Vanderbilt University, and Washington University in St. Louis for helpful comments on and suggestions for previous drafts of this paper. Special thanks to Teresa Britton for her patience in discussing the ideas in this paper and her very helpful comments on a penultimate draft.
} 
Choi, Sungho and Michael Fara (2006/2012). "Dispositions" in Edward N. Zalta, ed., Stanford Encyclopedia of Philosophy, https://plato.stanford.edu/entries/dispositions/

Elder, Crawford (2007). "Realism and the Problem of Infimae Species" American Philosophical Quarterly 44: 111-27

Evnine, Simon (2016). Making Objects and Events: a Hylomorphic Theory of Artifacts, Events, and Organisms (Oxford: Oxford UP)

Dumsday, Travis (2010) "Natural Kinds and the Problem of Complex Essences" Australasian Journal of Philosophy 88: 619-34

Dutilh, Novaes Catarina (2012). "Reassessing Logical Hylomorphism and the Demarcation of Logical Constraints" Synthese 185: 387-410

Fine, Kit (1994). “Compounds and Aggregates” Noûs 28: 137-58

Fine, Kit (1999). “Things and Their Parts” Midwest Studies in Philosophy 23: 61-74

Hawley, Katherine and Alexander Bird (2011). "What Are Natural Kinds?” Philosophical Perspectives 25: 205-21

Hawthorne, John (2001). “Causal Structuralism” Pbilosophical Perspectives 15: 361-78

Heil, John (2003). From an Ontological Point of Vien (New York: Oxford UP)

Heil, John (2012). The Universe As We Find It (New York: Oxford UP)

Heil, John (forthcoming). "Hylomorphism: What's Not to Like?” Synthese

Jaworski, William (2016). Structure and the Metaphysics of Mind: How Hylomorphism Solves the Mind-Body Problem (New York: Oxford)

Johnston, Mark (2006). “Hylomorphism” Journal of Philosophy 103: 652-98

Koons, Robert (2014). "Staunch vs. Faint-Hearted Hylomorphism: Toward an Aristotelian Account of Composition" Res Philosophica 91: 151-77

Koons, Robert and Timothy Pickavance (2017). The Atlas of Reality: A Comprehensive Guide to Metaphysics (Malden, M.A.: Wiley-Blackwell)

Koslicki, Kathrin (2008). The Structure of Objects (New York: Oxford UP)

Lewis, David (1986). “Against Structural Universals” Australasian Journal of Philosophy 64: 25-46

Lewis, David (1997). “Finkish Dispositions” Philosophical Quarterly 47: 143-58

Lowe, E.J. (1999). “Abstraction, Properties, and Immanent Realism” in T. Rockmore, ed., Proceedings of the Twentieth World Congress of Philosophy, Volume II: Metaphysics (Bowling Green, O.H.: Philosophy Documentation Center), 195-205

Lowe, E.J. (2006). The Four-Category Ontology: A Metaphysical Foundation for Natural Science (New York: Oxford UP) 
Marmodoro, Anna (2013). “Hylomorphism Without Reconditioning” Philosophical Inquiry 36: 5-22

Martin, C.B. (1994). "Dispositions and Conditionals" Philosophical Quarterly 44: 1-8

Martin, C.B. (2008). The Mind in Nature (New York: Oxford UP)

Martin, C.B. and Karl Pfeifer (1986). "Intentionality and the Non-Psychological" Philosophy and Phenomenological Research 46: 531-554

McDaniel, Kris (2010). "Parts and Wholes" Philosophy Compass 5: 412-25

Mumford, Stephen (1998). Dispositions (New York: Oxford UP)

Oderberg, David (2007). Real Essentialism (New York: Routledge)

Oderberg, David (2011). "Essence and Property" Erkenntnis 75: 85-111

Oderberg, David (2014). “Is Form Structure?” in David Novotny \& Lucas Novak, eds., Neo-Aristotelian Perspectives in Metaphysics (New York: Routledge), 164-80

Paul, L.A. (2002). “Logical Parts” Noûs 36: 578-96

Pasnau, Robert (2010). "Form and Matter" in Robert Pasnau \& Heather van Dyke, eds., The Cambridge History of Medieval Philosophy (Cambridge: Cambridge UP), 635-46

Rea, Michael (2011). "Hylomorphism Reconditioned” Philosophical Perspectives 25: 341-58

Scaltsas, Theodore (1994). Substances and Universals in Aristotle's Metaphysics (Ithaca, N.Y.: Cornell UP)

Schaffer, Jonathan (2003). "The Problem of Free Masses" Philosopby and Phenomenological Research 66: 125-138

Schaffer, Jonathan (2004). “Two Conceptions of Sparse Properties” Pacific Pbilosophical Quarterly 85: 92-102

Schaffer, Jonathan (2005). “Quiddistic Knowledge” Philosophical Studies 123: 1-32

Schaffer, Jonathan (2010). "Monism: The Priority of the Whole" Philosophical Review 119: 31-76

Skrzypek, Jeremy (forthcoming). "From Potency to Act: Hyloenergism” Synthese

Swoyer, Chris (1996). “Theories of Properties: From Plentitude to Paucity” Philosophical Perspectives 10: 243-64

Thomasson, Amie (2010). “The Controversy over the Existence of Ordinary Objects” Philosopby Compass 5: 591-601

Tugby, Matthew (2013). "Platonic Dispositionalism” Mind 122: 451-80

Vetter, Barbara (2014). "Dispositions without Conditionals" Mind 123: 129-56 